2 Suttorp-Schulten MSA, Koornneef L. Linear scleroderma associated with ptosis and motility disorders. Br $\mathcal{O}$ Ophthalmol 1990;74:694-5.

3 Lehman TJA. The Parry-Romberg syndrome of progressive facial hemiatrophy and linear scleroderma en coup de sabre. Mistaken diagnosis or overlapping conditions? \& Rheumatol 1992;19: $844 n 5$.

4 Olver J, Laidler P. Acquired Brown's syndrome in a patient with combined lichen sclerosus atrophicus and morphoes. $\mathrm{Br}$ \% Ophthalmol 1988;72:552-7.

5 Blodi FC, Gass JDM. Inflammatory pseudotumour of the orbit. Br $\mathcal{O}$ Ophthalmol 1968;52:7993.

6 Kennerdell J, Dresner S. The nonspecific orbital inflammatory syndromes-review. Surv Ophthabmol 1984;29:93-103.

7 Cline RA, Rootman J. Enophthalmos: a clinical review. Ophthalmology 1984;91:229-37.

8 Kirkali PA, Kansu T, Sanac AS. Unilateral enophthalmos in systemic scleroderma. I Clin Neuro-Ophthalimol 1991;11:43-4.

9 Enzmann D, Donaldson SS, Marshall WH, Kriss JP. Computed tomography in orbital pseudotumour (idiopathic orbital inflammation). Radiology 1976;120:597-601.

10 Atlas SW, Grossman RI, et al. Surface-coil MR of orbital pseudotumour. Am $\mathcal{Y}$ Neuroradiol 1987;8: $141-6$.

\section{Primary orbital fibrosarcoma developing in the scleral stroma}

EDrToR,-Fibrosarcomas are thought to be malignant tumours developing from fibroblasts. ${ }^{1}$ Primary fibrosarcoma of the orbit is very rare. For example, only five cases were reported among a total of 986 orbital tumours in adults. ${ }^{2}$ Recently we encountered the case of primary orbital fibrosarcoma attached to the posterior pole of the globe, the posterior wall of which was encapsulated with fibrous tissue similar to the sclera, although the tumour had infiltrated the posterior pole of the globe and the optic nerve sheath. The fibrosarcoma in this case is thought to have developed in the scleral stroma.

\section{CASE REPORT}

A 56-year-old woman was first referred to our clinic for examination of an intraconal tumour of the left eye. On admission her visual acuity was 20/20 in the right eye and 2/200 in the left eye, with correction. There was no record of previous radiation therapy and no history of orbital injury. The main ophthalmoscopic findings were the presence of marked choroidal folds, disc oedema, and optociliary shunt vessels in the left eye. Systematic and haematological investigations revealed no abnormalities. Results of computed tomography of the orbit showed a relatively well defined intraorbital mass attached to the posterior pole of the globe (Fig 1). In axial T1 weighted magnetic resonance images, the posterior wall of the tumour was though to be encapsulated (Fig 2). The tumour was not invasive towards the retrobulbar space; however, it had partially infiltrated the scleral stroma. The posterior pole of the globe was compressed and flattened by the tumour. In sagittal $T 1$ weighted images, it was observed to compress the optic nerve; its boundary towards the optic nerve sheath was partially blurred. Pathologically, the tumour was composed of interlacing bands of spindle-shaped cells forming a herringbone pattern (Fig 3). The number of mitoses was three per ten high-power fields $(x$ 450). Immunohistochemical staining for vimentin was positive, indicating that the tumour had originated from mesodermal cells. The tumour was infiltrated into the sclera and into the optic nerve sheath. Up to about 1 year after the exenteration, no recurrence of the tumour had been detected.
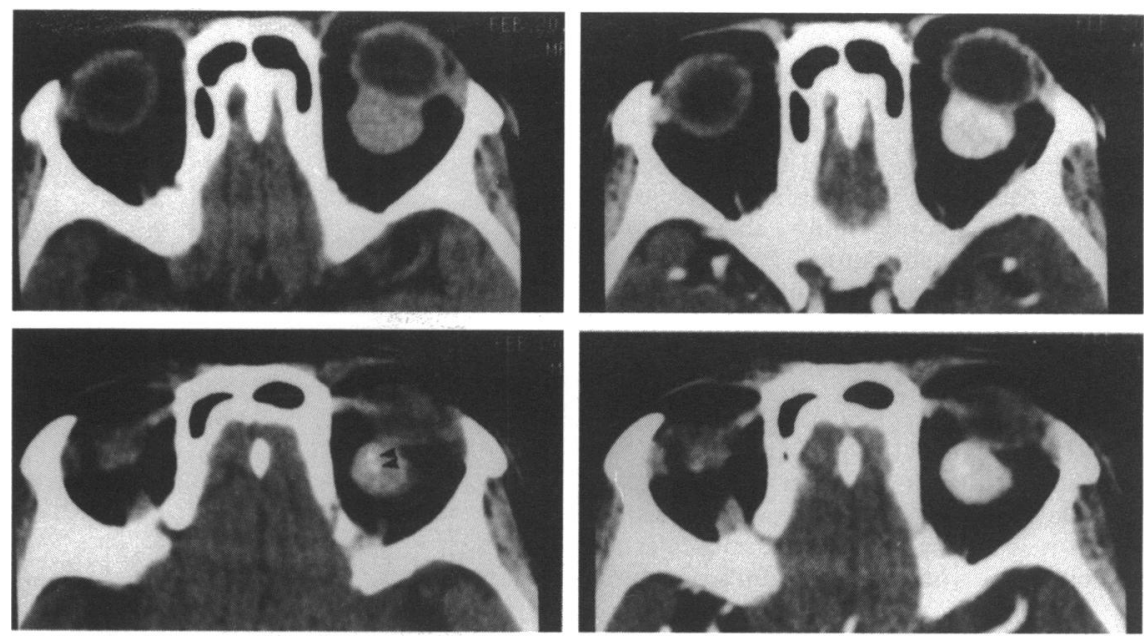

Figure 1 Axial plain (right) and enhanced (left) computed tomographic scans of the orbit. Arrowheads indicate calcification in the tumour.
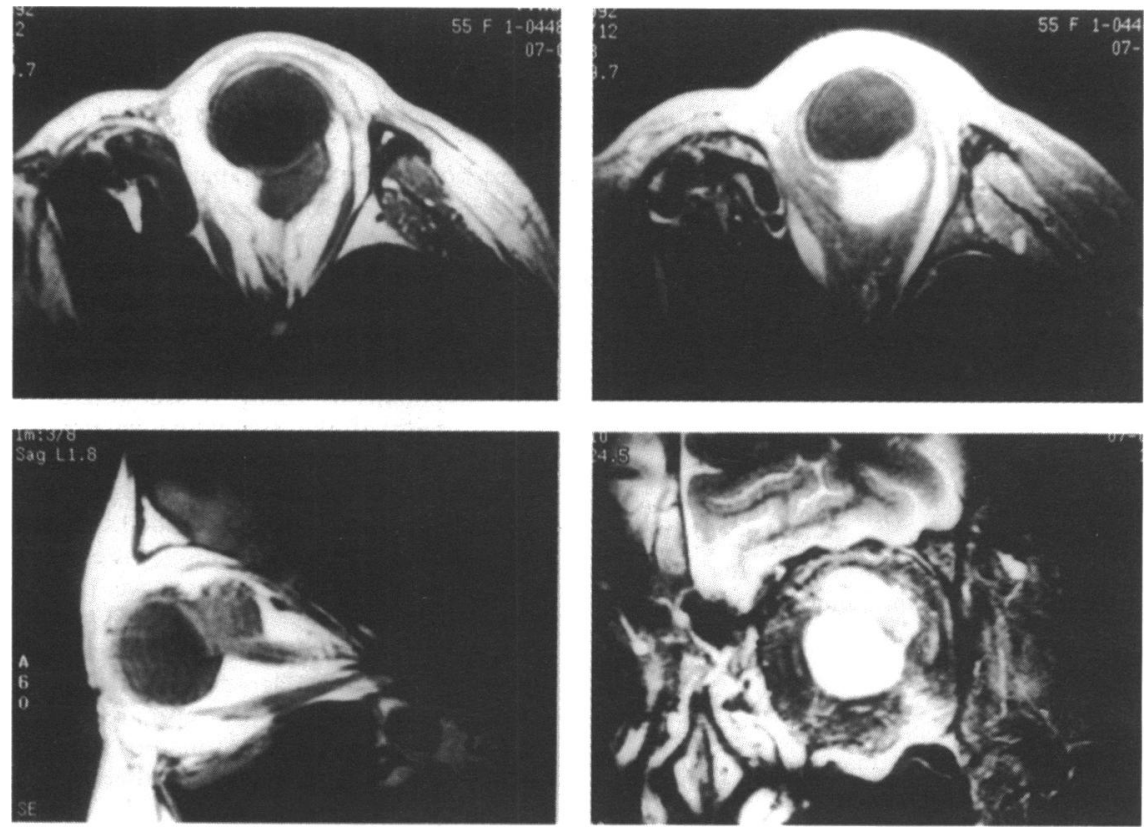

Figure 2 Magnetic resonance images of the orbit. Axial T1 image (top left) shows that the posterior wall of the tumour was encapsulated and that the tumour compressed and flattened the posterior pole of the globe. The boundary of the tumour towards the globe was irregular and partially blurred. The tumour was enhanced homogeneously with gadolinium-DTPA (top right; axial T1 image with fat suppression). The tumour had compressed the optic nerve sheath as well as the globe (bottom left; sagittal $T 1$ image). The intensity of the tumour is inhomogeneous in $T 2$ image (bottom right; coronal T2 image).
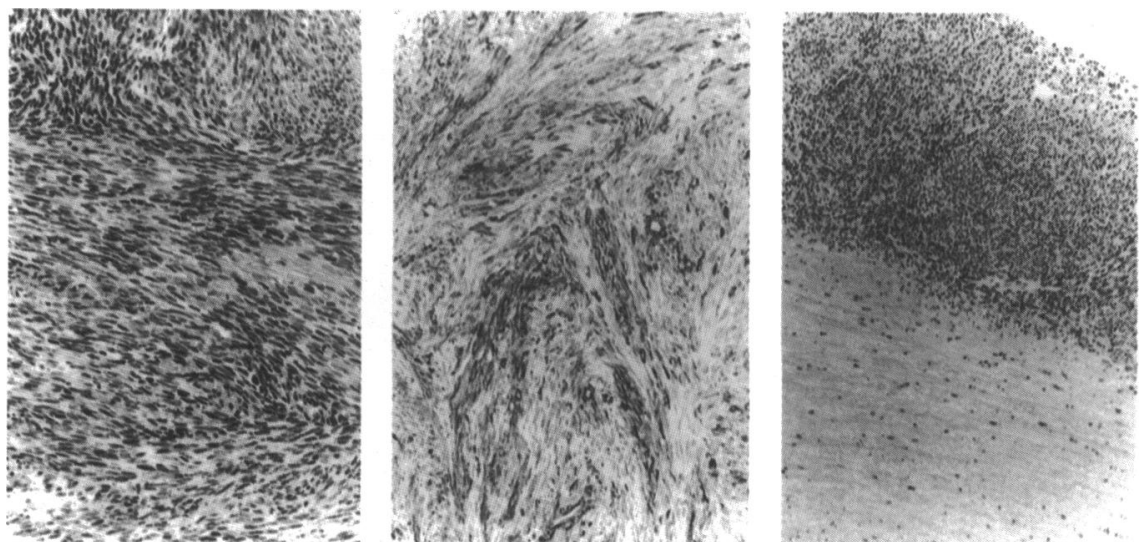

Figure 3 Photomicrographs of the tumour. Spindle-shaped cells arranged in characteristic herringbone pattern (left; haematoxylin and eosin, $\times 120$ ). Immunohistochemical staining of the tumour for vimentin was positive (middle; $\times 120$ ). The right panel shows that tumour cells (upper part of the section) had infiltrated the sclera (lower part of the section) (haematoxylin and eosin, $\times 40)$ 


\section{COMMENT}

Microscopic analysis of the tumour indicated that it was a fibrosarcoma. Many fibrosarcomas in previous reports were described as non-encapsulated or poorly circumscribed..$^{3-5}$ In contrast, the tumour in this case had unique radiological and pathological features. Results of computed tomography of the orbit showed a relatively well defined mass attached to the posterior pole of the globe. The magnetic resonance imaging and pathological findings indicated that the fibrosarcoma in this case developed primarily in the scleral stroma and was invasive in the sclera.

KENII OHTSUKA KUMI SAITO

Department of Ophthalmology Sapporo Medical University,

School of Medicine Sapporo, Hokkaido, fapan

Correspondence to: Dr Kenji Ohtsuka, Department of Ophthalmology, Sapporo Medical University, School of Medicine, S-1, W-16, Chuo-ku, Sapporo 060, Japan.

Accepted for publication 28 June 1996

1 Stout AP. Fibrosarcoma: the malignant tumor of fibroblasts. Cancer 1948;1:30-59.

2 Forrest AW. Intraorbital tumors. Arch Ophthalmol 1949;43:198-232.

3 Yanoff $M$, Scheie $H$. Fibrosarcoma of orbit. Cancer 1966;19:1711-6.

4 Jakobiec FA, Tannenbaum $M$. The ultrastructure of orbital fibrosarcoma. Am f Ophthalmol 1974; 77:899-917.

5 Scott SM, Reiman HM, Pritchard DJ, Ilstrup DM. Soft tissue fibrosarcoma: a clinicopathologic study of 132 cases. Cancer 1989;64:92531 .

\section{CORRESPONDENCE}

\section{A new mounting bracket for donor eye holder}

EDrToR,-Morphometry of corneal endothelial cells is now recognised as indispensable for evaluation of corneal function in many clinical and research situations. ${ }^{1}$ It may be performed by physical counting of endothelial cells within a rectangular boundary from specular photomicrographic negatives, or with digitisers and image analysers which require manual tracing of the cell boundaries or their apices after endothelial specular photomicrography. ${ }^{2}$ These methods are time consuming, tedious, and liable to human error and bias.

Advances in instrumentation and computer technology have resulted in new contact and non-contact semiautomatic clinical specular microscopes ${ }^{3}$ which feature an autofocusing device for instant acquisition of endothelial images. In addition, some have an inbuilt semiautomatic image analysis programs, while yet others have been adapted for use with separate computers which provide rapid and comprehensive analysis of cell variables. These improvements have eased the tedium and drudgery of the earlier methods, ${ }^{2}$ and minimised the elements of human error and bias.

Furthermore, evaluation of the corneal endothelium in the presence of significant stromal oedema has become a practical reality with the advent of the confocal microscope. ${ }^{4}$ It would be desirable to take advantage of these advances in the context of donor cornes assessment and morphometry.

Donor eye holders for supporting the intact globe for specular microscopy have been dedi-

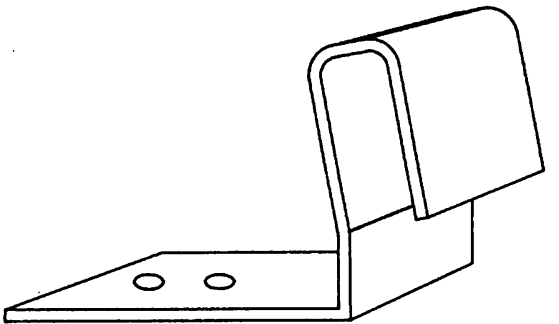

Figure 1 Diagram of the mounting bracket.

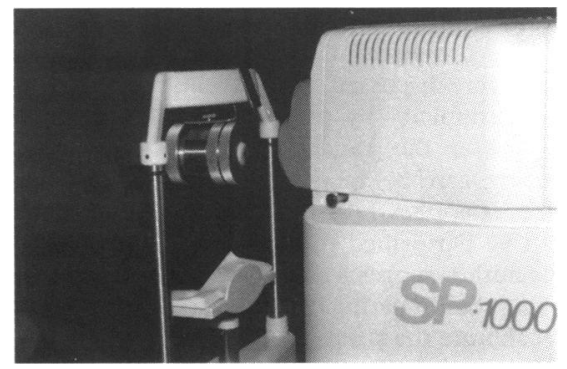

Figure 2 Photograph of eye holder with a globe in situ mounted on a non-contact specular microscope by means of the bracket for morphometry of the corneal endothelium.

cated to particular instruments, ${ }^{5-7}$ and are, therefore, not interchangeable. In addition, they may not fit the new semiautomatic contact and non-contact specular microscopes. This makes it difficult to harness the advantages of the various specular microscopes and to compare them. A universal holder for supporting the intact globe which can be attached to most clinical microscopes would be useful and desirable.

Given the limitations of the donor eye holders which have been dedicated to particular specular microscopes, and the need to take advantage of recent advances in morphometric analysis with the new semiautomatic specular microscopes, in the context of donor cornea assessment and morphometry, I have designed, produced, and tested a new and simple mounting bracket for the Nartey donor eye holder. ${ }^{8}$

The mounting bracket (Fig 1) is made of brass and consists of flat horizontal and vertical limbs. The horizontal limb bears two holes at its distal end. The vertical limb is inclined slightly backwards at its upper two thirds, and angled forwards at its proximal end for attachment to a headrest. Either hole on the horizontal limb can be aligned with that for a thumbscrew halfway up the side of the eye holder. The mounting bracket is attached to the eye holder by first engaging the aligned holes with the thumbscrew. Tightening the thumbscrew secures the mounting bracket firmly to the side of the holder.

This permits the holder, without its base plate, but with a donor eye in situ, to be attached horizontally to the headrest of contact and non-contact specular microscopes (Fig 2) for visualisation, assessment, photography, and/or morphometric analysis of the donor corneal endothelium in the intact globe.

A smaller mounting bracket of similar design, but with a narrower angle at the proximal end of its vertical limb, can be used with the Haag-Streit slit-lamp and the tandem scanning confocal microscopes which have a plastic headrest.

It is believed this innovation is an advance and should facilitate research and objective assessment of the donor cornea in the intact globe.
I am very grateful to Mr Roger Buckley for reading the manuscript and for his helpful suggestions. I thank Mrs Ann Patmore and MrN Wingate for permission to use the confocal and the S-P 1000 (Topcon) microscopes, and Mr P Johnson for technical assistance. Moorfields Eye Bank, Moorfields Eye Hospital City Road, London EC1V 2PD

1 Siertsema JV, Landesz M, Van Den Brom, Van $\mathrm{Rij}$ G. Automated video image morphometry of the corneal endothelium. Doc Ophthalmol 1993;85:35-44.

2 Waring GO, Ford GE, Harris RR, Rosenblatt LS Four methods of measuring human corneal endothelial cells from specular micrographs. Arch Ophthalmol 1980;98:848-55.

3 Landesz M, Siertsema J V, Van Rij, G. Comparative study of three semi-automated specular microscopes. $\mathcal{F}$ Cataract Refract Surg 1995;21: 409-16.

4 Lemp FB, Dilly PN, Boyde A. Tandem confoca microscopy of full thickness cornea. Cornea 1985/86;4:205-9.

5 Hoefle FB, Maurice DM, Sibley RC. Human donor material: a method of examination before keratoplasty. Arch Ophthalmol 1970;84:741-4.

6 Bigar F, Schimmelpfennig B, Gieseler R. Routine evaluation of endothelium in human donor corneas. Graefes Arch Klin Exp Ophthalmol 1976; neas. Graefes

7 Matsuda M, Yee RW, Glasser DB, Geroski DH, Edelhauser HF. Specular microscopic evaluation of donor corneal endothelium. Arch Oph thalmol 1986;104:259-62.

8 Nartey IN. Mastering the infant donor eye: a new device for obtaining corneoscleral buttons for storage and corneal discs for keratoplasty. $\mathrm{Br} f$ Ophthalmol 1991;75:38-41.

\section{BOOK REVIEWS}

The Eye: Basic Sciences in Practice. By J V Forrester, A D Dick, P McMenamin W $R$ Lee. Pp 320. £45. London: W B Saunders, 1995 .

Here is a textbook which seeks to guide the novice trainee ophthalmologist on the path to success in primary professional examination(s). It tackles, in a simple didactic style, the rudiments of anatomy, embryology, genetics, biochemistry, physiology, pharmacology, immunology, microbiology, and pathology. Candidates will find it a concise review of information learnt in medical school and not long forgotten.

By far the most useful chapters are those on biochemistry, pharmacology, and immunology. These are clearly written, and are pitched at exactly the right level. Topics of contemporary research have been dealt with in an admirably lucid manner, such as integrins, extracellular matrix proteins and proteoglycans, adhesion molecules, ligand/receptor/second messenger systems, retinal neurotransmitters, cytokines, immunoglobulin genes, cluster of differentiation (CD) numbers, and $T$ cell receptors.

The sections on biochemistry and immunology make good use of a format which has been common in American books: 'boxes' demarcate from the main text a number of detours which provide helpful glossaries and encyclopaedia-type entries on supplementary and background information. In the pharmacology section, and in an attractive and concise chapter on microbiology, the boxes 